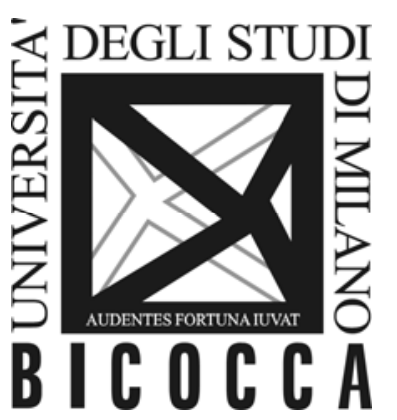

\author{
DEPARTMENT OF ECONOMICS, \\ MANAGEMENT AND STATISTICS \\ UNIVERSITY OF MILAN - BICOCCA
}

DEMS WORKING PAPER SERIES

\title{
Does it take two to tango? How to improve cooperation between the IMF and the World Bank
}

Silvia Marchesi and Laura Sabani

No. 232 - September 2012

Dipartimento di Economia, Metodi Quantitativi e Strategie di Impresa Università degli Studi di Milano - Bicocca http://dems.unimib.it/ 


\title{
Does it take two to tango? How to improve cooperation between the IMF and the World Bank
}

\author{
Silvia Marchesi* \\ Università di Milano Bicocca
}

\author{
Laura Sabani \\ Università di Firenze
}

September 2012

\begin{abstract}
Despite a series of official agreements aimed at strengthening Bank-Fund cooperation, it is widely believed that coordination between the two organizations often falls short of what should be rationally expected. In this paper we present a theoretical model which, focusing on the quality of information transmission between the IMF and the WB, analyzes the impact of different governance structures on the degree of Bank-Fund cooperation. We compare the performance of a "delegation-scheme" with that of a "centralization-scheme." A centralized structure better addresses the necessity of coordinating policy actions but greater consistency between the Bank and the Fund policy actions will be achieved at the expenses of a less satisfactory adaptation to "local conditions." When the need for coordination is relevant, as it is generally the case for the Bank and the Fund operations, we find that a centralized governance structure allows to achieve a level of overall payoff greater than those of a decentralized one.
\end{abstract}

Keywords: IMF and WB conditionality, coordination, communication JEL Classification: D83, F33, N2.

${ }^{*}$ We thank Rune Hagen for useful comment and suggestions. We also thank participants at the Political Economy of the International Organization (PEIO) Annual Meeting (Heidelberg and Mannheim, 2013). The usual caveat applies. Corresponding author: Silvia Marchesi, Dipartimento di Economia Politica, Piazza dell'Ateneo Nuovo 1, I-20126 Milano. Tel. +39 026448 3057; Fax. +39 026448 3085; E-mail: silvia.marchesi@unimib.it. 


\section{Introduction}

The International Monetary Fund (IMF) and the World Bank (WB) were originally created as two distinct and independent institutions with complementary tasks and different methods of intervention, within the framework of the Bretton Woods agreement (1944). Over the years, however, their mandates have expanded in response to the changing realities of the global economy and the degree of overlap between the two has increased, leading to more room for both conflict and cooperation.

Despite a series of official agreements aimed at strengthening Bank-Fund cooperation, it is widely believed that coordination between the two organizations often falls short of what should be rationally expected. However, little theoretical and empirical analyses exist about what factors inhibit or encourage cooperation between the IMF and the WB. In this paper we try to fill this gap by presenting a theoretical model which, focusing on the quality of information transmission between the two institutions, analyzes the impact of different governance structures on the degree of Bank-Fund cooperation.

Many public documents and reports have stressed that more cooperation and coordination between the Bank and the Fund is crucial to exploit potential synergies and to avoid potential sources of conflicts which could jeopardize the success of their adjustment programs. The degree of coordination depends critically on the degree of communication between the two organizations. In the past, the Bank and the Fund used to adhere to certain recipes for reforms (the so called Washington Consensus), and have prescribed many conditions of their policy lending accordingly. However, as Birdsall and Kapur (2005) have emphasized, the notion of an agreed set of policy recommendations no longer exists and as the reform agenda has deepened to include institutional and social reforms it has become apparent that a "top-down" approach does not produce sustained reforms.

The current trend, on the contrary, puts a greater emphasis on incorporating countryspecific inputs (the so called "local knowledge") and on promoting country ownership in the formulation of policy proposals, which in turn requires greater engagement of borrowing governments. Indeed, as emphasized by Dixit (2009), Easterly (2006, 2008), Rajan (2008) and Marchesi et al. (2011), institutions, organizations, and policies are context-specific and thus International Financial Institutions (IFIs) have been urged to base their recommended policy changes (conditions) on a good understanding of the structure and properties of the recipient country's institutional, political and economic context. ${ }^{1}$

Although local knowledge is vital to the definition of economic problems and their prac-

\footnotetext{
${ }^{1}$ For example, according to Woods (2006), sustained reforms require a deeper commitment or support from the broader political system and society.
} 
ticable solutions, it is well known that it political intractable, and very difficult to make judgments about (Wood, 2006). In other words, local knowledge often consists of unverifiable information (or verifiable only at a cost). Such a shift from a well defined framework to guide conditions for policy lending, substantially based on "hard information," towards a situation where conditions more and more are related to "soft" information has important implications for the interaction and future cooperation between the Bank and the Fund. Indeed, we can expect that, whenever the objectives of the two institutions are not completely aligned, the information transmitted will be distorted, since both institutions will use communication strategically to influence decision making to their favour.

The misalignment of interests between the Bank and the Fund arises when decision making involves a trade off between coordination and adaptation to "local conditions." ${ }^{2}$ Although the extent of overlap between the operations of the two organizations have incraesed over time, they still maintain a strongly specialized expertise in their core areas of intervention: monetary, fiscal, and exchange rate policies for the Fund and policy areas related to development for the Bank. Therefore, each institution bases its decision on specialized information that is only partially overlapping. A greater pressure for conformity, required by the need of coordination, may contrast with the objective of enhancing policy adaptation to the specific conditions revealed by each institution's specialized expertise. ${ }^{3}$

In our paper we compare two types of organizational structure: centralization vs decentralization. We define as "centralized" an organization in which control rights over policies are allocated to an "headquarter" which decides policy recommendations after receiving the Fund and the Bank suggestions relative to their respective core area of intervention (vertical communication). On the contrary, with "decentralization" we refer to the existing organizational structure, in which control rights are retained by the two institutions (in each own sphere of influence), and the coordination between the two is left to the discretion of their executive boards (horizontal communication).

The headquarter maximizes overall "payoffs" (given by the sum of the Bank and the Fund objective functions), while under "decentralization" each executive board maximizes its own objective function. Contrary to the headquarter, the executive board of each institution does

\footnotetext{
${ }^{2}$ The increasing emphasis in policy lending on country specificity and ownership now implies that not only should the Bank and Fund cooperate more but they should also deliver the policy advice that suits best borrowing governments. On that respect, the Bank seems to have adapted better and faster to such requirements through an more decentralized and flexible operational model than the Fund.

${ }^{3}$ Fabricious (2007) empirically shows that whenever the Bank and the Fund agree on the boundaries of each other's operations (the so called "domain consensus"), they tend to speak with one voice. However, the increasing overlap of the mandates of the two organizations over time has amplified the areas of potential conflict, since each institutions tends to exaggerate the importance of their own opinions overlooking the importance of compromise.
} 
not fully internalize the benefits of coordination, since it does not internalize how its actions affect the other institution. Therefore, a centralized structure better addresses the necessity of coordinating policy actions. This intuition, however, overlooks the fact that the headquarter is uninformed and must rely on the specialized information transmitted by the Bank and the Fund to take decisions. Differently from a decentralized structure, where communication is crucial to improve coordination, in a centralized structure communication is fundamental to improve adaptation. But the misalignment of interests between the headquarter and the single institutions prevents vertical communication to be truthful. Thus, adaptation losses are always higher in a centralized governance than in a decentralized one.On the other hand, the decisions taken by the headquarter are not biased by the selfishness of the two institutions, as it happens instead in a decentralized structure. Therefore, the coordination losses are always lower.

Consequently, in a centralized governance, a greater consistency between the Bank and the Fund policy actions will be achieved at the expenses of a less satisfactory adaptation to "local conditions." However, when the need for coordination is relevant, as it is generally the case for the Bank and the Fund operations, given their strong complementariness, we find that a centralized governance allows to achieve a level of overall payoffs greater than those of a decentralized one. ${ }^{4}$

This result is in line with the empirical results by Marchesi and Sirtori (2011) who, estimating the impact on economic growth of the simultaneous participation in both IMF and WB programs, find that such interaction between these two organizations has a positive and significant impact on growth. This result is also in line with the general wisdom that centralization must be preferred when the need for coordination is relevant, and it supports the reform proposals which have favorably looked at a possible merger between the two institutions. $^{5}$

The paper is organized as follows. Section 2 contains some institutional information regarding the overlapping responsibilities of the IMF and the WB while Section 3 briefly describes the related literature. Section 4 presents the theoretical model and finally Section 5 concludes.

\footnotetext{
${ }^{4}$ As Krueger (1997) puts it: "a strong case can be made that the functions of lending policy advice training research and provision of information of both the Bank and the Fund are mutually complementary and that the spillovers from each of the functions to the others are large."

${ }^{5}$ See for example, Clark (1990); Crook (1991); Shultz (1998); Burnham (1999) and Fischer (2004).
} 


\section{IMF and the World Bank: synergies and conflict}

The World Bank and the IMF were created as two distinct and independent institutions with different tasks and methods of intervention, within the framework of the Bretton Woods agreement (1944). Up to the 1980s, the division of labor between the Fund and the Bank had been relatively straightforward. While the Fund's orientation was towards short-run macroeconomic stability, the Bank was oriented towards long-run development programs. At the same time the existence of synergies between the two institutions has also been recognized. Such synergies, however, became become more important during the 70's and the 80 's when, on the one hand, the IMF started to complement demand management policies by supply side policies and, on the other, the World Bank changed its policy towards a more explicit recognition of the importance of macroeconomic policies besides the traditional project and sector lending. ${ }^{6}$ Moreover, during the 1980s, the Fund's lending became more concessional and related to structural matters and increasingly focused on lower income countries, those typically "served" by the Bank.

The first step toward a formal recognition of the importance of cooperation between the IMF and the World Bank was already made in 1966 with an agreement which explicitly laid out the primary responsibilities of each organizations and the procedures for the two to work together (Boughton, 2001). ${ }^{7}$ Then, in 1974, the Development Committee (DC) was established, it is a joint ministerial committee of the Boards of Governors of the Bank and the Fund in charge of advising both institutions on critical development issues and on the financial resources required to promote economic growth in developing countries. The Committee should assure high-level coordination and facilitate intergovernmental consensusbuilding on development issues.

Lately, in 1989, a Concordat was signed by the IMF and the World Bank in which a vast area of overlapping responsibilities was explicitly identified. In this common area, cooperation should have been pursued and strengthened: to this scope the Concordat did define guidelines and terms of the World Bank-Fund interaction, and the mechanisms for resolving potential conflicts between the sister organizations. Both institutions committed themselves to systematically exchange information concerning low and middle-income countries. More-

\footnotetext{
${ }^{6}$ Between 1980 and 1984 energy prices were addressed in $46 \%$ of Fund supported programs, the mobilization of domestic savings in 54\% investment planning and execution in $37 \%$. These were areas of primary responsibility of the Bank. Similarly the Bank was increasingly concerned with many variables central to Fund stabilization program (Feinberg, 1988)

${ }^{7}$ According to the Dual memoranda of December 1966, the need for collaboration is made explicit by giving numerous examples of overlapping responsibilities: the structure and functioning of financial institutions, the adequacy of money and capital markets, the actual and potential capacity of a country to generate domestic savings, the implications of development programs for the internal and external financial position of a country (Gold,1982).
} 
over, the Concordat encouraged them to exchange this information not only within their decision bodies, but also at the level of the operative staff. We should emphasize that the Concordat was motivated by the public nature of the disagreement between the Fund and the Bank about Argentina, in 1988. At that time, the rules on collaboration broke down when the World Bank announced a new loan to the country, before the IMF mission had completed its negotiations with the Argentinian authorities. This circumstance forced the two organizations to come up with a new agreement to guide collaboration (Wood, 2006).

Later on, in 1988, during the Asian Crisis, a new episode of disagreement promoted the issuing of a joint statement by the Bank president and the Fund managing director on Bank-Fund collaboration. In light of the greater overlap in operations, the leaders of the two organizations reaffirmed that a better collaboration was needed.

Despite all these official documents aimed at strengthening Bank-Fund cooperation, operations in middle-income countries are not yet guided by any formal collaborative vehicle. As a result, the Bank and the Fund cooperation hinges critically on discretional communication at the staff level. The case is different for low income countries. With the creation of the Structural Adjustment Facility (SAF) and the Enhanced Structural Adjustment Facility (ESAF), later substituted by the Poverty Reduction and Growth Facility (PRGF), structural adjustment has served to create an important area of overlap between the Bank and the Fund. ${ }^{8}$ To access this program the country has to elaborate a policy framework paper, that is the Poverty Reduction Strategy Paper (PRSPs), jointly with the staff of the Fund and the Bank. The process of drafting the PRSPs was designed to ensure the consistency of the Bank's and the Fund's stances, by forcing them to develop a common view on the appropriate policy advice for the country. ${ }^{9}$

Despite good intentions PRSPs revealed some weaknesses such as the asymmetry in the documents' operational importance in each organization, the lack of specificity in outlining policy targets, and the failure to effectively engage the borrowing government in the process. Most notably, this latter weakness with the PFP process underscored the need for more substantial country involvement and pushed the Bank and the Fund to acknowledge country ownership as an emerging priority of development cooperation. By many standards, country ownership had come to be considered an important component of successful poverty reduction

\footnotetext{
${ }^{8}$ In January 2010, three types of loans were created under the new Poverty Reduction and Growth Trust (PRGT) as part of a broader reform: the Extended Credit Facility (ECF), the Rapid Credit Facility (RCF) and the Standby Credit Facility (SCF). In particular, the ECF succeeds the PRGF as the Fund's main tool for providing medium-term support.

${ }^{9}$ In the same year, the Heavily Indebted Poor Countries (HIPC) initiative was enhanced as a direct outcome of a comprehensive review carried out by the International Development Association (IDA) and the IMF. The initiative entails a coordinated commitment to reduce and forgive large volumes of debt to the poorest and most indebted countries.
} 
and development (IMF and World Bank 2001). ${ }^{10}$

More recently, in 2007 the World Bank and the Fund signed a Joint Management Action Plan, which sets concrete steps to improve the culture of cooperation between the two institutions, emphasizing, on the one hand, that duplicate functions represent a waste of resources for both institutions and, on the other, that uncoordinated policy prescriptions can make it harder for recipients dealing with adjustment programs. The Plan calls for an improvement of coordination and communication and it also recommends to translate identified good-practices concerning interaction into standard practices.

The issue of Fund Bank coordination is still debated nowadays and far form being settled. For example, the forthcoming IMF review of conditionality is expected to contain a fair amount of discussion of coordination with the World Bank. This is going to be crucial especially for middle income countries whose operations are not guided by any formal process, like the PRSP or the related facilities in the two organizations.

\section{Related literature}

This paper is related to three strands of literature. The first is the literature on strategic information transmission, which is built on the seminal paper by Crawford and Sobel (1982), hereafter CS. More specifically, we are related to the literature on coordination in organizations under distributed information (Alonso, Dessein and Matouschek, 2008, hereafter ADM; Rantakari, 2008). These authors address the problem of an organization in which two operating divisions (managers) should adapt to local conditions but also coordinate with each other. Coordination must rely on communication, since managers are privately informed about their local conditions. The need to balance conflicting needs for adaptation creates conflicting preferences and, as result, communication will be distorted since both divisions will try to influence decision making to their favour, using communication strategically. Under this framework two different governance structure are analyzed: a centralized and a decentralized one. The results of ADM and Rantakari confirm the general wisdom that when coordination needs are relevant, a centralized structure in which decision rights are allocated to an headquarter, should be preferred, although adaptation to local conditions will be always less satisfactory than in a decentralized structure.

The second stream of literature which we relate to is primarily concerned with the governance of the IFIs. While there are many papers dealing with both the IMF and the WB individually, to our knowledge, there are very few papers analyzing what governance struc-

\footnotetext{
${ }^{10}$ For example, in its review of program performance, the Funds Policy Development and Review Department (PDR) found that a substantial proportion of program interruptions had been attributable to policy disagreements between governments and the Fund staff (IMF 1998).
} 
ture may inhibit or encourage cooperation between the IMF and the WB. More specifically, there is no contribution addressing this problem theoretically. ${ }^{11}$ Fabricius (2007), drawing on field research conducted in Ghana, Pakistan, Peru, and Vietnam, over the period 198096, has tried to identify empirically the conditions that determine whether or not these organizations are actually collaborating, addressing as well whether such collaboration is necessarily a good thing. According to Fabricius' results, Bank-Fund cooperation (or consistency) depends critically on the level of communication between the two organizations, where such exchange of information is not generally institutionalized but it has been let to the discretion of individuals (i.e., the staff members). ${ }^{12}$ Whether or not the Bank and the Fund cooperate has been found to depend on two conditions, which are highly correlated. Namely, similarity in the Bank's and the Fund's organizational structures (which facilitates communication) and the so called "domain consensus" (i.e. the degree to which they consent to the domain of their respective activities in the division of labor). ${ }^{13}$ Finally, an important implication emerging from this study is that Bank-Fund consistency may not always be desirable. According to Fabricious, pressures for conformity might jeopardize "ownership" of lending conditions and thus he suggests that the Bank and the Fund should pursue a case-specific approach in deciding whether or not to coordinate.

A similar problem is also addresses by Hagen (2010), who asks how "ownership" could be affected by introducing more or less donors' coordination. Indeed in the case of multiple (uncoordinated) donors greater coordination (especially in the case of a "lead lender" and of a silent partner) could generate some pressure for conformity, which may contrast with the objective of enhancing recipients' ownership.

In both papers a trade off between responding to local conditions (i.e., improving "ownership") and coordination among donors, clearly emerges. However, the problem of what governance structure may better respond to such trade off is not addressed. In this paper we propose to fill the gap by applying the analysis of ADM and Rantakari (2008) to analyse the impact of different governance structures on the degree of Bank-Fund cooperation.

The third and final strand of literature we look at is empirical. Despite a vast literature considering the individual impact of the IMF and the WB on recipient countries' economic

\footnotetext{
${ }^{11}$ Some political scientists have addressed the issue of the efficiency of the separation between the Fund and the Bank, arguing that these two global economic institutions, created for very different purposes, are nowadays indistinguishable for all intents and purposes,and their artificial separation is inefficient (e.g., Clark, 1990; Crook, 1991; Shultz, 1998; Burnham, 1999 and Fischer, 2004).

${ }^{12}$ The main exception being the PRSPs which are prepared by the countries themselves together with the World Bank and the IMF. However, this only applies to low-income countries.

${ }^{13}$ Moreover, the evidence collected at the country level suggests that the most difficult factor that Bank and Fund staff must overcome to ensure domain consensus is the difference between the two organizations' operational styles (the Fund remains a highly centralized organization while the Bank has gradually decentralized its operations to the borrowing countries).
} 
growth and development, little is known about the effects of the simultaneous presence of both institutions in a single country. Moreover, little empirical evidence exists about how and under what circumstances these two organizations work actually together. It is therefore difficult to distinguish the effect of their interaction from that of their simultaneous action, which may in itself have an effect. Marchesi and Sirtori (2011) have estimated the impact on economic growth of the joint participation in both IMF and WB programs. As a proxy of Bank-Fund interaction they used the simultaneous presence of a Bank and Fund program in the same country and at the same time. ${ }^{14}$ More specifically, using panel data for 128 developing countries over the period 1982-2005, and employing 2SLS to control for the possible endogeneity of participation in an IMF/WB program, Marchesi and Sirtori find that the interaction between these two organizations has a positive and significant impact on growth. More specifically, the coefficient of IMF programs is negative and significant, the coefficient of World Bank programs is not significant while the coefficient of their interaction term is positive and significant at conventional levels. The results suggest that the WB can have a stronger impact on growth when the IMF is simultaneously involved as compared to when it is acting individually.

\section{The model}

Over the years the evolution of the Fund and the Bank has generated an expansion of their respective "areas of expertise," which does require a stronger coordination between their actions in order to exploit all their potential synergies. At the same time, the increasing importance of "local knowledge" in designing sustainable reforms and the greater overlap between their "areas of action," has also brought about an increase in competition between the two institutions. More competition tend to make each institutions overlook the importance of compromise. ${ }^{15}$ As a consequence, the need to balance conflicting needs for adaptation creates conflicting preferences in many areas of intervention and, in taking their decisions, both the Fund and the Bank must now balance the benefits of setting their actions closer either to those of the other decision maker (coordination) or to their idiosyncratic "state of nature" (adaptation).

\footnotetext{
${ }^{14}$ Being involved simultaneously with the same country does not necessarily mean that these two organizations are actually working together. The Bank and Fund could lend simultaneously to the same country without any exchange of information as well as exchanging information also at a distance. However, ceteris paribus, it is plausible to believe that these institutions will be more likely to interact when simultaneously "involved" with the same country as compared to the case in which they are acting on their own.

${ }^{15}$ This may depend on either the lack of domain consensus, making both the Fund and the Bank exaggerate the importance of their opinion on the issue at the stake, or to the growing importance that "local conditions" -as revealed by each institution's specialized information- have been acquiring in tailoring adjustment programs to recipients' needs.
} 
This general problem has been formally modelled by ADM by referring to an organization with two distinct divisions. In the following we refer to a simplified version of their model. More specifically, differently from them, we assume that the two divisions (the Fund and the Bank in our context) are fully selfish. ${ }^{16}$ We believe that this scenario better describes a situation in which the public evaluation of the two institutions' operations responds exclusively to their own performance. The notation we use follows ADM.

\subsection{Objective functions}

The trade off between coordination and adaptation can be formalized by assuming that the Fund and the Bank have to minimize the following quadratic loss functions, respectively:

$$
\begin{aligned}
& L^{F}=\left(d_{1}-\theta_{1}\right)^{2}+\delta\left(d_{1}-d_{2}\right)^{2} \\
& L^{B}=\left(d_{2}-\theta_{2}\right)^{2}+\delta\left(d_{2}-d_{1}\right)^{2}
\end{aligned}
$$

where $d_{1}$ represents the Fund's decision, $d_{2}$, represent the Bank's decision and $\theta_{i} \in R$, $i \in\{1,2\}$, represents the "specialized information" of each institutions. The Fund observes its "local conditions" $\theta_{1}$ without knowing the Bank's "local conditions" (i.e., the realization of $\theta_{2}$ ) and viceversa. It is common knowledge that $\theta_{1}$ and $\theta_{2}$ are uniformly distributed on $\left[-\bar{\theta}_{i}, \bar{\theta}_{i}\right]$, and the draws of $\theta_{1}$ and $\theta_{2}$ are independent. The first term of the loss function represents the loss due to a not satisfactory adaptation to local conditions, that is $d_{i} \neq \theta_{i}$, while the second term represents the coordination loss that the Fund (and the Bank) incurs when their actions are not perfectly coordinated, that is $d_{1} \neq d_{2}$.

The parameter $\delta \in[0, \infty)$ measures the relative weight of coordination losses with respect to adaptation losses. If the degree of competition between these two institutions is high, $\delta$ will be low, namely the two institutions overlook the need to coordinate their action in order to improve the adaptation to "local conditions." On the contrary, if the gain from exploiting synergies is high, $\delta$ will be high. The degree of the "environmental volatility" which is faced by the IMF is given by the variance of $\theta_{1}$ (i.e., $\sigma_{1}^{2}$ ), while that of the Bank is given by the variance of $\theta_{2}$ (i.e., $\sigma_{2}^{2}$ ).

\subsection{Delegation versus centralization}

Under a decentralized governance structure, control rights over $d_{1}$ and $d_{2}$ are allocated to the IMF and the WB, respectively. Each of them will take decisions to minimize its own loss

\footnotetext{
${ }^{16}$ The selfishness of the two institutions might be explained by the circumstance that the career of both the Fund and the Bank staff members depend on skills and efforts which are exclusively related to the performance of each institution.
} 
function, overlooking the effect which its own action has on the other institution. Thus, we assume that the Fund and the Bank first observe their local conditions, then they send each other messages $m_{1}$ and $m_{2}$ about the realization of their own state of nature, and finally they take their decisions to minimize respectively $E\left[L^{F} \mid \theta_{1}, m_{2}\right]$ and $E\left[L^{B} \mid \theta_{2}, m_{1}\right]$.

Under a centralized governance structure, control rights over $d_{1}$ and $d_{2}$ are retained by a central authority, the Headquarter (HQ), that is not informed about the "local conditions". The HQ acts in behalf of global taxpayers and therefore takes decisions $d_{1}$ and $d_{2}$ to minimize the following loss function:

$$
L^{H Q}=L^{F}+L^{B}
$$

Before taking decisions the HQ receives messages $m_{1}$ and $m_{2}$ about the realization of the two states on nature from the Fund and the Bank, respectively, and then it takes decisions $d_{1}$ and $d_{2}$ to minimize $E\left[L^{H Q} \mid m_{1}, m_{2}\right]$.

\subsection{Decision making}

We analyze decision making by assuming both a centralized and a decentralized governance structure.

Under centralization, the HQ receives messages by the Fund and the Bank and then chooses $\left(d_{1}, d_{2}\right)$ to minimize $E\left(L^{H Q} \mid m=\left(m_{1}, m_{2}\right)\right)$. Taking the first order conditions of the expected value of (3) with respect to $d_{1}$ and $d_{2}$, and solving for the equilibrium decisions, it is possible to show that:

$$
\begin{aligned}
& d_{1}^{C}=\gamma E\left(\theta_{1} \mid m\right)+(1-\gamma) E\left(\theta_{2} \mid m\right) \\
& d_{2}^{C}=(1-\gamma) E\left(\theta_{1} \mid m\right)+\gamma E\left(\theta_{2} \mid m\right)
\end{aligned}
$$

where:

$$
\gamma=\frac{1+2 \delta}{1+4 \delta}
$$

The equilibrium decisions are convex combination of the HQ's posterior beliefs about the states of the fundamentals $\theta_{1}$ and $\theta_{2}$, conditional on the vector $m$. When the importance of coordination increases and eventually when $\delta \longrightarrow \infty$ the HQ sets:

$$
d_{1}^{C}=d_{2}^{C}=\frac{1}{2}\left[E\left(\theta_{1} \mid m\right)+E\left(\theta_{2} \mid m\right)\right] .
$$

Under decentralization, taking the first order conditions of the expected value of (1) and (2) with respect to $d_{1}$ and $d_{2}$, deriving the reaction functions and solving them for the 
equilibrium decisions, yields:

$$
d_{1}^{D}=a \theta_{1}+(1-a)\left(b E\left(\theta_{1} \mid \theta_{2}, m\right)+(1-b) E\left(\theta_{2} \mid \theta_{1}, m\right)\right)
$$

and:

$$
d_{2}^{D}=a \theta_{2}+(1-a)\left(b E\left(\theta_{2} \mid \theta_{1}, m\right)+(1-b) E\left(\theta_{1} \mid \theta_{2}, m\right)\right)
$$

where $a=\frac{1}{1+\delta}$ and $b=\frac{\delta}{1+2 \delta}$.

The Fund decision is a convex combination of $\theta_{1}$ and its posterior beliefs about $\theta_{2}$ (i.e., $\left.E\left(\theta_{2} \mid \theta_{1}, m\right)\right)$, and the Bank posterior belief about $\theta_{1}$, (i.e., $E\left(\theta_{1} \mid \theta_{2}, m\right)$ ).

Similarly, the Bank decision is a convex combination of $\theta_{2}$ and its posterior beliefs about $\theta_{1}$, (i.e., $E\left(\theta_{1} \mid \theta_{2}, m\right)$ ), and the Fund posterior belief about $\theta_{2}$, (i.e., $E\left(\theta_{2} \mid \theta_{1}, m\right)$ ). As $\delta \rightarrow \infty$, for given posterior beliefs, the decentralized decisions converge to that of the HQ, that is:

$$
d_{1}^{D}=d_{2}^{D}=\frac{1}{2}\left[E\left(\theta_{1} \mid m\right)+E\left(\theta_{2} \mid m\right)\right]
$$

in other words, as the need of coordination increases, the misalignment between the objectives of the HQ and those of both the Fund and the Bank disappears.

\subsection{Strategic Communication}

To improve coordination between their own specialized decisions, the Fund and the Bank can communicate the realization of their observed state of nature before taking action. However, the non-verifiability of information (i.e., soft information) creates communication problems. Under both organizational structures the information transmitted will never be truthful: indeed, there will always be an incentive for either the Fund or the Bank to exaggerate the realization of the state of nature with a positive bias if $\theta_{i}>0$ and with a negative bias if $\theta_{i}<0$, with $i=1,2 .^{17}$

Let us consider first the case of a decentralized structure. Let us suppose that the Fund sends message $m_{1}$ to the Bank. The Bank's expected response to message $m_{1}$ is given by $(1-a)(1-b) E\left(\theta_{1} \mid \theta_{2}, m\right)$, with $(1-a)(1-b)<1$. In this case, the Fund, anticipating Bank's behavior, will try to induce a higher "reaction" by the Bank, by exaggerating the value of the report about the realized $\theta_{1}$. It is straightforward to show that only when $\theta_{1}=0$ communication will be truthful. The same argument applies to the Bank.

The incentives to misrepresent information exists also in a centralized governance structure. Indeed, the HQ puts more weight on minimizing the coordination losses than the Fund

\footnotetext{
${ }^{17}$ This is the typical setting of a cheap talk models where agency problems prevents communication from being sincere (CS). Each agent introduces a distortion in its message in order to manipulate the choice of the other.
} 
or the Bank would like it to do. If for example the Fund truthfully communicate $\theta_{1} \neq 0$ to the $\mathrm{HQ}$, it would expects that the latter would take decision $d_{1}^{C}=\gamma E\left(\theta_{1} \mid m\right)$, which, from its point of view, would not be "extreme" enough, given that $E\left(\theta_{2}\right)=0$ and $\gamma<a+(1-a) b$. As a consequence, the Fund will exaggerate the realization of $\theta_{1}$ by reporting $m_{1}>\theta_{1}$ (if $\theta_{1}>0$ ) or $m_{1}<\theta_{1}$ (if $\theta_{1}<0$ ). It is straightforward to show that only when $\theta_{1}=0$ communication will be truthful. The same argument applies to the Bank.

The incentives to mis-report information are qualitatively the same in both governance structure, but it is possible to show that as the need for coordination increases (that is, as $\delta$ increases) the quality of information (horizontal communication) transmitted under a decentralized governance structure increases, while it worsens in a centralized governance structure (vertical communication). Intuitively, in a decentralized structure an increase in the need of coordination makes both agents more responsive to the communicated information, since they put less weight on adapting decisions to their own "local conditions." This circumstance reduces the incentives to exaggerate information. In contrast, in a centralized structure, as the need for coordination increases, the HQ becomes less and less responsive to communicated information. This explains why the Fund's (or Bank's) incentive to exaggerate information increases.

Moreover, when $\delta=0$, the need to balance conflicting needs for adaptation disappears in both types of governance structure. In the case of centralization, vertical communication will be fully truthful, that is: $m=\theta, d_{1}^{C}=\theta_{1}$ and $d_{2}^{C}=\theta_{2}$; while in the case of decentralization, communication becomes totally uninfluential, since both institutions will only put weight on the adaptation to their respective local conditions, namely: $d_{1}^{D}=\theta_{1}$ and $d_{2}^{D}=\theta_{2}$. Therefore, the two governance structure will produce the same results.

Finally, as $\delta \rightarrow \infty$, for given posterior beliefs, the decentralized decisions converge to that of the HQ, as in equation (8) above.

\subsection{Communication Equilibria}

We model the coordination game of an organization with two divisions where decisions must both be adapted to local conditions and coordinated with each other. Information about local conditions is private, soft and communicated by cheap talk. ADM show that all communication equilibria are interval equilibria in which the state space, $\left[-\bar{\theta}_{i}, \bar{\theta}_{i}\right], i=1,2$, are partitioned in intervals, and each division reveals only which interval its local conditions $\theta_{i}$ belong to. ${ }^{18}$ The equilibrium concept used is Perfect Bayesian Equilibrium (PBE). A PBE

\footnotetext{
${ }^{18}$ The contribution of Alonso et al is an extension of the famous CS contribution on cheap talk games.Crawford and Sobel focus on the amount of information that will be communicated by an informed agent, assuming that the principal makes the decision and that its preferences are only partially aligned with
} 
equilibrium consists of a reporting strategy $\mu_{1}\left(m_{1} \mid \theta_{1}\right)$ for the Fund and a reporting strategy $\mu_{2}\left(m_{2} \mid \theta_{2}\right)$ for the Bank, given a probability distribution over reports $m_{i}$ conditional on the value of $\theta_{i}$ observed, and a posterior belief functions $g_{i}\left(\theta_{i} \mid m_{i}\right)$, satisfying $\frac{\mu_{i}\left(m_{i} \mid \theta_{i}\right)}{\int}$ for $\int_{P} \mu_{i}\left(m_{i} \mid \theta_{i}\right) d \theta_{i}$

$i=1,2$, given the posterior probability of $\theta_{i}$ conditional on each possible report $m_{i}$.

The decision rule, under decentralization, is given by the functions $d_{1}^{C}\left(m_{1}, m_{2}\right), d_{2}^{C}\left(m_{1}, m_{2}\right)$ reported in (4) and (5)); while, under decentralization, the decision rule is given by the functions $d_{1}^{D}\left(\theta_{1}, m_{2}\right), d_{2}^{D}\left(m_{1}, \theta_{2}\right)$, reported in (6) and (7)).

For an interval equilibrium to be incentive compatible, it is necessary that, when the realized state falls on the boundary of two intervals of the partition, the sender must be indifferent between saying that the state belongs to either one of the intervals. This condition translates in a differential equation whose solution defines the following family of incentivecompatible partitions:

$$
\begin{gathered}
a_{i, j+1}-a_{i, j}=a_{i, j}-a_{i, j-1}+4 b_{h} a_{i, j} \\
\left.a_{i,-(j+1}\right)-a_{i,-j}=a_{i,-j}-a_{i,-(j-1)}+4 b_{h} a_{i,-j}
\end{gathered}
$$

for $j=1,2 \ldots \ldots N_{i}-1$, where $N_{i}$ is the number of intervals.

Conditions (9) and (10) say that the size of the interval $\left(a_{i, j+1}-a_{i, j}\right)$ is equal to the size of the preceding interval $\left(a_{i, j}-a_{i, j-1}\right)$ plus $4 b_{h} a_{i, j}$; symmetrically, in the negative semiaxis, the size of the interval $\left.\left(a_{i,-(j+1}\right)-a_{i,-j}\right)$ is equal to that of the preceding interval plus $4 b_{h} a_{i,-j}$. It is possible to show that $b_{h}=b_{C}=\frac{\delta}{1+\delta}$ under centralization and $b_{h}=b_{D}=\frac{1+\delta}{\delta}$ under decentralization.

The quality of communication deteriorates as $\theta_{i}$ moves further away from its mean value, that is $\theta_{i}=0$. This result is intuitive since the incentives to misrepresent information increase with the module of $\theta_{i}$. Furthermore, we can see that $b_{C}$ increases with $\delta$, while $b_{D}$ decreases with $\delta$. Consistently with what intuitively explained in the previous subsection, this means that in a centralized governance, communication becomes noisier when the need of coordination (i.e., $\delta$ ) increases, while in a decentralized governance, communication becomes more precise. However, it is possible to check that $b_{C} \leq b_{D}, \forall \delta$. This implies that in a centralized structure the quality of communication is always higher than in a decentralized organization, although this difference is decreasing with the importance of coordination. This result is easily explained by noting that the misaligment of interests between the Bank and the Fund is always greater than the misaligment between the HQ and each single institution.

those of the agent. 
$\mathrm{ADM}$ prove that the limit of strategy profiles and beliefs as the number of partitions $N_{i} \rightarrow \infty$ is a PBE, and it is the most efficient equilibrium, that is $E L^{H Q}=E\left(L^{F}+L^{B}\right)$ is lower than in any other equilibrium. In such an equilibrium the size of the intervals is infinitesimally small for $\theta_{i}$ close to 0 and increases at a growing rate as the module of $\theta_{i}$ increases.

\subsection{The choice of governance}

In this section we compare the expected losses for each governance structure.

Under centralization, the HQ has got control over both the Fund and the Bank operations. Since its objective is to minimize overall losses, the decisions it takes are always first best, conditional on the information available. The amount of adaptation achieved depends on the importance of adaptation for the two institutions, which in turn depends on the quality of the information released. Instead, the amount of coordination depends on the overall value of coordination.

Let $A L_{C}$ denote the adaptation losses, that is:

$$
A L_{C}=E\left[E\left(\theta_{2}-d_{2}^{C}\right)^{2}+\left(\theta_{1}-d_{1}^{C}\right)^{2}\right]
$$

and let $C L_{C}$ denote the coordination losses, that is:

$$
C L_{C}=E\left(d_{1}^{C}-d_{2}^{C}\right)^{2}
$$

Expected losses under centralization are thus given by:

$$
E L_{C}=A L_{C}+2 \delta C L_{C}
$$

Under decentralization, the Fund and the Bank take decisions overlooking the effects of their actions on the other's payoff. Equilibrium decisions are thus biased with respect to the first best even under perfect information. Moreover, strategic communication leads to coordination failures over and above any inherent biases in equilibrium decisions.

Let $A L_{D}$ denote the adaptation losses, that is:

$$
A L_{D}=E\left(\left(d_{1}^{D}-\theta_{1}\right)^{2}+E\left(d_{2}^{D}-\theta_{2}\right)^{2}\right.
$$

and let $C L_{D}$ denote the coordination losses, that is:

$$
C L_{D}=E\left(d_{1}^{D}-d_{2}^{D}\right)^{2}
$$


Expected losses under dentralization are thus given by:

$$
E L_{D}=A L_{D}+2 \delta C L_{D}
$$

ADM prove that that the adaptation losses (AL) are always higher in a centralized governance structure, while the coordination losses (CL) are always higher in a decentralized governance structure, that is

$$
\begin{gathered}
A L_{C}-A L_{D}=\triangle A L \geqq 0 \forall \delta \in[0, \infty) \\
C L_{D}-C L_{C}=\triangle C L \geq 0 \forall \delta \in[0, \infty)
\end{gathered}
$$

Differently from a decentralized structure, where communication is fundamental to improve coordination, in a centralized structure communication is fundamental to improve adaptation. But the misalignment of interests between the headquarter and the single institution prevents vertical communication to be truthful. This explains why adaptation losses are always higher in a centralized governance structure than in a decentralized one. On the other hand, in a decentralized structure, decisions are biased by the selfishness of the two institutions, and strategic communication leads to further coordination failures. Therefore, the coordination losses are always higher in a decentralized structure.

As the need for coordination increases, the worse performance of the centralized governance structure in terms of adaptation to local conditions is fully offset by the better results that it can achieve under coordination. This is proved in the following proposition.

Proposition 1 Centralization dominates decentralization for all $\delta \geq 0.19$ Moreover, $E L_{C}-$ $E L_{D}=0$ when $\delta=0 ; E L_{C}-E L_{D} \rightarrow 0$ when $\delta \rightarrow \infty$.

Proof. It is possible to show that by substituting, $a, b, \gamma, S_{C}, S_{D}$ for their expressions that

$$
E L_{C}-E L_{D}=\triangle A L+\triangle C L=2 \delta\left(\sigma_{1}^{2}+\sigma_{2}^{2}\right) \frac{33 \delta^{3}+32 \delta^{2}+3 \delta-2}{392 \delta^{5}+1078 \delta^{4}+1125 \delta^{3}+560 \delta^{2}+133 \delta+12}
$$

Let $f=33 \delta^{3}+32 \delta^{2}+3 \delta-2$

since the denominator of $E L_{C}-E L_{D}$ is always positive, it is easy to check that :

$$
\operatorname{sign}\left(E L_{C}-E L_{D}\right)=\operatorname{signf} ; \quad f \geq 0 \forall \delta \in[0.19, \infty) .
$$


The proposition shows that a decentralized authority represents the preferred governance structure only when the need of coordination is very low. In this case, the advantages of a decentralized structure in achieving a better adaptation are greater than the disadvantages of a biased decision.

In contrast, a centralized governance structure should be preferred when the coordination need is above a given threshold level. The HQ is able to eliminate the bias arising in decentralized equilibrium, although the quality of adaptation remains always below of what can be achieved under a decentralized structure.This disadvantage, however, is fully offset by the better coordination results that a centralized structure can guarantee. As the need of coordination increases further, each institution becomes more willing to coordinate with the other. Thus, the dominant position of a centralized structure is "eroded" by the circumstance that even in a decentralized structure the decisions become less and less biased. To the limit (as $\delta$ tends to infinity) the outcomes of the two governance structures converge to the same value. The same result is obtained when $\delta=0:$ in this case there is no need to balance competing adaptation needs: the absence of conflicting preferences allows then to achieve the first best in both types of governance structures.

\section{Conclusions}

Despite a series of official agreements aimed at strengthening Bank-Fund cooperation, it is widely believed that coordination between the two organizations often falls short of what should be rationally expected. However, a greater pressure for conformity, required by the need of coordination, may contrast with the objective of enhancing policy adaptation to the specific conditions revealed by each institution's specialized expertise.

In this paper we present a theoretical model which, focusing on the quality of information transmission between the IMF and the WB, analyzes the impact of different governance structures on the trade off between responding to local conditions (i.e., improving "ownership") and the need of enhancing consistency of policy actions. We compare the performance of a decentralized governance structure with that of a centralized one. A centralized structure better addresses the necessity of coordinating decisions, but a greater consistency between the Bank and the Fund policy actions will be achieved at the expenses of a less satisfactory adaptation to "local conditions."

We find that a decentralized structure is to be preferred only when the need for coordination is very low. The better performance of the centralized governance structure is mainly due to the selfishness nature of the two institutions: since their reputation exclusively depends from their own performance, they systematically overlook the impact of their 
actions on the other organization's payoff. Therefore, their policy choices will result always "too distant" with respect to the First Best. This drawback more than offsets the better adaptation to "local conditions" that a decentralized structure can achieve. Maintaining a decentralized structure, this result suggests that the introduction of partial incentive alignments between the two organizations could reduce the underlying agency problem and thus ameliorate overall outcomes.

The paper could be extended in two directions. First of all, we plan to analyze the case of asymmetric interdependency. Indeed, as many authors have emphasized, the Fund seems to be less inclined to coordination than the Bank. For example, Fabricious (2007) has argued that while the WB' structural adjustment loans (SALs) and project lending may await the borrower's agreement with the Fund, the IMF's stand by negotiations have generally been independent from the Bank' opinion ${ }^{19}$ Moreover, the WB has often argued that a structural adjustment program would fail without consistent macroeconomic policies designed to correct external equilibrium misadjustments. Therefore, an asymmetric setting will be more useful in order to investigate the different (relative) importance of adaptation and coordination for the two institutions.

A further extension of our basic framework is related to the issue of the acquisition of costly information. In the framework of coordination games based on cheap talk communication, the specialized information privately owned by agents is generally assumed to have been costlessly collected. However, when the acquisition of specialized information is costly, agents must balance the cost of information acquisition against its benefits. In our framework the benefits are only related to the improved adaptation to "local conditions." Thus, it would be interesting to analyse the impact that different governance structures may have on the agents' incentive to invest in acquiring informative signals.

\section{References}

[1] Alonso R., Dessein D. W., and N. Matouschek (2008) "When does Coordination Require Centralization?" American Economic Review, 98, 145-179

[2] Birdsall N., and D. Kapur (2005) "The Hardest Job in the World: Five Crucial Tasks for the New President of the World Bank." Washington: Center for Global Development.

[3] Boughton, J. (2001) "Silent Revolution: The International Monetary Fund, 19791989." Washington: International Monetary Fund.

\footnotetext{
${ }^{19}$ The withholding of Fund's credit may affect a member's budget enough to disrupt financing for a Bank's supported project, but not vice versa.
} 
[4] Burnham J.B. (1999) "The IMF and World Bank: time to merge" The Washington Quarterly, 22, 101-111.

[5] Clark Jr. Lindley H. (1990). "Let's Merge the World Bank and the IMF". Wall Street Journal, 4 January.

[6] Crook, Clive (1991). "Sisters in the Wood - A Survey of the IMF and the World Bank". The Economist, 12 October.

[7] Crawford, V., and J.Sobel. (1982) "Strategic Information Transmission." Econometrica, 50, 1431-1451.

[8] Dixit, A. (2009) "Governance, Institutions and Economic Activity." American Economic Review 99, pp. 5-24.

[9] Easterly, W. (2006) "The White Man's Burden: Why the West's Efforts to Aid the Rest Have Done So Much Ill and So Little Good." London: The Penguin Press.

[10] Easterly W. (2008) "Institutions: Top Down or Bottom Up?", American Economic Review, Papers and Proceedings, 98, 95-99.

[11] Fabricius M. (2007) "Merry Sisterhood or Guarded Watchfulness? Cooperation Between the International Monetary Fund and the World Bank", WP $07-9$ Peterson Institute for International Economics.

[12] Fischer F. (2004) "Thinking the Unthinkable: Combining the IMF and World Bank" The International Economy Fall

[13] Feinberg,Richard (1988) "The changing relationship betwwen the World Bank and the International Monetary Fund" International Organizations vol . 42, n.3 :545-56

[14] Gold, Joseph (1982) " The relationship between the International Monetary Fund and the World Bank" Creighton L.Rev. vol .15: 499 -521

[15] Hagen R. (2010) "Dancing the H-Street Waltz? Policy Choice in Aid-Dependent Countries", mimeo

[16] IMF (1998). External Evaluation of Enhanced Structural Adjustment Facility (ESAF): Report by a Group of Independent Experts

[17] Krueger, A. (1997) "Wither the World Bank and the IMF?" NBER Working Paper 6327. 
[18] Mallaby The world banker

[19] Marchesi S., Sabani L. and A. Dreher (2011), "Read my lips: the role of information transmission in multilateral reform design", Journal of International Economics, 2011, Volume 84, pp. 86-98

[20] Marchesi S, Sirtori E. (2011) "Is two better than one? Effects on growth of Bank-Fund interaction" Review of International Organization, 2011, Volume 6, pp 287-306

[21] Rantakari, H. (2008) "Governing Adaptation." Review of Economic Studies, Vol. 75, Issue 4: $1257-1285$

[22] Rajan, R. (2008) "The future of the IMF and the World Bank" American Economic Review, Papers and Proceedings, 98, 110-115.

[23] Shultz, G. P. (1998). "Merge the IMF and World Bank". The International Economy. January/February: 14-16.

[24] Woods N. (2006) "The Globalizers. The IMF, the World Bank, and their Borrowers." Cornell University Press.

[25] Wohlmuth,Karl (1984) "IMF and World Bank structural adjustment policies:Cooperation or Conflicts? "Intereconomics, September-October: 226-235

[26] World Bank and IMF (2001) Strengthening IMF-World Bank Collaboration on Country Programs and Conditionality (August).

[27] World Bank and IMF (2007) Final Report of the external review committee on BankFund collaboration (February). 